\title{
Sareari adimena gehitzen: machine learning eta gaitasun kognitiboen sarrera sare-mailako monitorizaziorako eta matxuren diagnostikorako
}

\author{
(Adding intelligence to the network: the integration \\ of machine learning and cognitive capabilities \\ at network level for monitoring and troubleshooting)
}

Ianire Taboada*, Bego Blanco

Bilboko Ingeniaritza Eskola (UPV/EHU)

*ianire.taboada@ehu.eus

DOI: $10.1387 /$ ekaia.17847

Laburpena: Ohiko sare-ereduak erabiliz belaunaldi berriko sareen ezaugarri espezifikoek ez dute kudeaketa egokia ahalbidetzen: izan ere, ezin ditu kontuan hartu eskala doiketa, heterogeneotasuna eta agertoki hauen konplexutasuna. Beraz, beharrezkoa da komunikazio sistema hauen diseinu eta kudeaketarako paradigma berriak definitzea. Modu honetan, machine learning-aren erabilpenaren bidez, sareari gaitasun kognitiboak gaineratzeak datuei erantsita sarean zehar garraiatzen den protokolo-informazioaren maneiatzea posible egiten du. Informazio hau sarearen egoera inferitzeko erabiltzen da, disfuntzioak ekidinez eta guztirako errendimendua hobetuz. Artikulu honek saremailan integratutako modulu adimentsu baten diseinua aurkezten du, offline machine learning-ean oinarrituz, bideraketa funtzionalitaterako informazioa bilduz eta interpretatuz. Testuinguruaz kontzientea den modulu kognitibo honek monitoreatutako sareegoeraren arabera bideraketa protokoloaren portaera manipulatzen du, horrela matxurak ekidinez, trafikoa orekatuz eta hobekuntza globala eskuratuz.

Hitz gakoak: machine learning, gaitasun kognitiboak, matxuren diagnostikoa, egokigarritasuna.

Abstract: The specific characteristics of next generation networks entail the impossibility of a proper management according to the conventional networking models, due to their inability to adjust the scale, the heterogeneity and the complexity of those scenarios. Therefore, it is necessary to define new paradigms to design and manage these 
emergent communication systems. At this point, adding cognitive capabilities to the network through the application of machine learning techniques makes it possible to leverage the protocol information that travels along the network attached to the data. This data is use to infer information about the state of the network and exploit it to prevent dysfunctions and improve the overall performance. This paper introduces the design of an intelligent module integrated at network level, based on offline machine learning, to gather and interpret information to complement and support the routing functionality. This context-aware cognitive module manipulates the behaviour of the routing protocol depending on the monitored state of the network to avoid failures, balance the traffic and get a global enhancement.

Keywords: machine learning, cognitive capabilities, troubleshooting, adaptiveness.

\section{SARRERA}

Informazio-sistemen bilakaerak bukaerako erabiltzaileei onura nabariak ematen die. Baina, honekin batera, egungo informazio-sistemen konplexutasun-hazkundea sare-paradigma tradizionalek eman dezaketenetik harago doa, sistema hauen hedapenari, kudeaketari eta mantenimenduari dagokionez. Belaunaldi berriko sareen arkitekturaren diseinu arrakastatsuak beharrezko erronka batzuk bete behar ditu, honako aspektu hauekin erlazionatuak: eskala handiko sistemen konplexutasuna, euren izaera dinamikoa, sare-baliabideen urritasuna, arkitektura heterogeneoak, kontrol eta azpiegitura zentralizatuaren falta eta matxuren konponketa autonomoen beharra.

Argi dago erronka horien jatorria konektibitate-eskaeraren eta trafikofluxuen hazkundean dagoela. Baina sarean zehar garraiatzen den datu-trafikoarekin batera, pakete bakoitzari erantsitako protokolo-goiburuek sarearen egoerari buruzko informazio adierazgarria dute. Aldi berean, sare-nodoetan exekutatzen ari diren protokolo-prozesuek sare-gertaeren eta haien emaitzen informazio adierazgarri ugari sortzen dute. Sareari informazio multzo hori hartzeko eta ustiatzeko ahalmena emateak sistemari autokudeaketa eta autoberreskurapen maila altuagoak eskuratzea ahalbidetzen dio, monitorizazio eta matxuren diagnostiko autonomo hobetuago baterako beharrezko baliabideak eskainiz.

Testuinguru honetan, machine learning-ean oinarritutako erremintek [1] rol nagusia jokatu dute ziklo kognitibo baten bidez orain arte sarearen «gainkarga» kontsideratu dena ezagutza baliagarrian transformatzeko prozesuan. Irrati-sare kognitiboen filosofian oinarrituz [2], kontzeptu hau protokolo askoren maila baxuetara hedatu da. Prozesu edo ziklo kognitiboek sistemei adimena ematen diete, horrela eskuragarri dagoen informazioa jasotzeko, aztertzeko eta sarearen dinamismoari aurre egiteko erabaki egokiena hartzeko. Ziklo kognitiboek giza ikasketa imitatzen dute eta zenbait fasez osatuta daude, datu-detekziotik hasi eta ezagutza berriaren sorre- 
Sareari adimena gehitzen: machine learning eta gaitasun kognitiboen sarrera sare-mailako monitorizaziorako eta matxuren diagnostikorako

rara arte. Hortaz, sare-sistemek disfuntzioak detekta ditzakete, klasifikatu eta matxurak ezabatu edota ekiditeko era autonomoan erabakiak hartzeko.

Artikulu honek aurreko metodologia sare mota espezifiko batean aplikatzen du, ad hoc sareak [3], zeinek berez autoantolaketa maila altua behar duten. Konkretuki, gaitasun kognitiboak sare-mailan sartzen dira machine learning eta erabakiak hartzeko prozesu banatu baten bidez, baliabideen erabilera eraginkorragoa egiteko eta disfuntzioen efektuak leuntzeko. Emaitza ad hoc sareentzat modulu kognitibo baten diseinua da, zeinek bideraketa-protokolo mota klasikoen ezaugarriak konbinatzen dituen, bakoitzaren abantailak hartuz eta desabantailak konpentsatuz. Bukaerako helburua edozein agertokitan errendimendu onena lortzea da, detektatutako sare-egoeraren arabera banakako nodoetan bideraketa protokoloaren portaera aldatuz.

Gainerako dokumentua horrela egituratzen da: hasteko, 2. atalean azaltzen da machine learning-eko gaitasun kognitiboen aplikazioa ad hoc sareko maila sarera; ondoren, 3. atalean lortutako emaitzak aurkezten dira; bukatzeko, 4. atalean emaitza nagusiak laburbiltzen dira.

\section{GAITASUN KOGNITIBOEN APLIKAZIOA SARE-MAILARA AD HOC SAREETAN}

Atal honek jauzi anitzeko ad hoc sareetan bideraketa funtzionalitatea gauzatzeko modulu kognitibo baten diseinua deskribatzen du. Helburua da edozein agertokitan errendimendu globala hobetzeko nodo bakoitzean detektatutako sare-egoeraren arabera bideraketa estrategia dinamikoki egokitzea. Lehenik eta behin, modulu kognitibo honen motibazioa eta helburuak aurkezten dira, eta ondoren, haren diseinua azaltzen da.

\subsection{Motibazioa eta helburuak}

Jauzi anitzeko ad hoc sareen berezitasuna azpiegitura finkoaren falta da. Konektibitate-alternatibak emateko, ad hoc sareek erabiltzaileen gailuak erabiltzen dituzte, ez bakarrik komunikazioaren bukaera-puntu bezala, baizik eta bitarteko transmisio-puntu bezala. Autoantolaketa honek eragindako malgutasunak eta gailu mugikorren orokortzeak, atea ireki diete aplikazio berri askori, zeinek sareak era espontaneoan edozein tokitan eta edozein lekutan sortzeaz aprobetxatzen diren. Konkretuki, ad hoc sareak soluzio indartsu bilakatu dira sentsore- eta ibilgailu-sareetan. Hala ere, ezaugarri hauek konplexutasuna handiagotzen dute, arrazoi hauengatik: sarearen hazkunde-eskala, ad hoc inguruneen izaera oso dinamikoa, gailu mugikorren baliabide eskasak, portaera banatua eta gailuen heterogeneitatea. 
Testuinguru honetan, ad hoc bideraketa gaiak erabakigarriak suertatzen dira sistemaren errendimendu globalari dagokionez. Ad hoc bideraketa funtzionalitatea sareko gailuen artean paketeak bideratzeko nodoek hartutako erabakiak kontrolatzean datza. Literaturak agertoki mota desberdinetan bideraketa-teknika desberdinak aztertzen dituen ikerketa ugari aurkezten ditu [4-5]. Dena den, nahiz eta agertoki espezifikoetan errendimendu ona erakusten duten proposamenak izan, ez dago helburu orokorreko soluziorik edozein agertokitan eta edozein aplikazio-esparrutan errendimendu-emaitza baliagarriak eskaintzen dituenik. Tamalez, honek ad hoc sareen bultzatzea zeharo zailtzen du. Hori dela eta, existitzen diren proposamenak hobetzeko, euren errendimendua degradatzen den agertoki horietan hobetzeko, beharrezkoa bilakatu da teknika berriak garatzea.

Gaitasun kognitiboak sare-mailan sartzeak nodo bakoitzean sarearen egoera detektatzea ahalbidetzen du, eta ondorioz, egoera espezifiko bakoitzean bideraketa teknika egokiena erabiltzera egokitzen da. Era honetan, guztiz segmentatutako ad hoc bideraketa izatearen eragozpenek aukera ematen diote jada proposatuta dauden bideraketa-estrategiak machine learning-ekin konbinatzeari.

Machine learning teknikak erabiliko duen proposatutako eredu kognitiboak bi ad hoc bideraketa mota klasikoren artean aukeratuko du: erreaktiboa eta proaktiboa. Protokolo erreaktiboek beharrezkoa denean soilik egiten dute bidearen bilaketa, eta proaktiboek, berriz, bideak periodikoki bilatzen dituzte (erabilgarriak direla uste izanez). Bideraketa mota horien abantailak eta desabantailak, zenbait agertokitarako/egoeratarako egokitasunarekin batera, 1. taulan aurkezten dira.

1. taula. Ad hoc bideraketa protokolo nagusien alderaketa.

\begin{tabular}{|c|c|c|c|}
\hline & Abantailak & Desabantailak & Egokitasuna \\
\hline Proaktiboa & $\begin{array}{l}\text { - Muturretik muturre- } \\
\text { rako atzerapen ba- } \\
\text { xuagoa. } \\
\text { - Bideraketa informa- } \\
\text { zioa beti egunera- } \\
\text { tuta. }\end{array}$ & $\begin{array}{l}\text { - Gainkarga gehiago. } \\
\text { — Eskalabilitate-ara- } \\
\text { zoak. }\end{array}$ & $\begin{array}{l}\text { - Erantzun azkarraren } \\
\text { beharra. } \\
\text { - Bide aktibo asko. } \\
\text { - Agertoki estatiko edo } \\
\text { apur bat dinamikoa. }\end{array}$ \\
\hline Erreaktiboa & $\begin{array}{l}\text { - Baliabideen erabil- } \\
\text { pen eraginkorra. } \\
\text { - Eskalabilitate ho- } \\
\text { bea. }\end{array}$ & $\begin{array}{l}\text { - Muturretik muturre- } \\
\text { rako atzerapen han- } \\
\text { diagoa. } \\
\text { - Topologia aldake- } \\
\text { tek denbora luzea- } \\
\text { goa behar dute egu- } \\
\text { neratzeko. }\end{array}$ & $\begin{array}{l}\text { - Bide aktibo gutxi. } \\
\text { - Atzerapena ez da kri- } \\
\text { tikoa. } \\
\text { - Agertoki dinamikoa. }\end{array}$ \\
\hline
\end{tabular}


Sareari adimena gehitzen: machine learning eta gaitasun kognitiboen sarrera sare-mailako monitorizaziorako eta matxuren diagnostikorako

Beraz, hemen aurkezten den sare-geruza kognitiboa modulu adimentsu batez osatuta dago. Modulu horrek bi bideraketa-estrategia horien artean aukeratzeko erabakia hartuko du detektatutako sare-egoeraren arabera, era dinamikoan. 2. taulak modulu kognitiboaren proposamenerako kontsideratutako helburu teknikoak laburbiltzen ditu, haiek lortzeko ezarritako diseinu-gidalerroekin batera.

2. taula. Modulu kognitiboaren helburu teknikoak eta diseinu-gidalerroak.

\begin{tabular}{|c|c|}
\hline Helburuak & Gidalerroak \\
\hline $\begin{array}{l}\text { 1. Kudeaketa banatua eta autoanto- } \\
\text { laketa }\end{array}$ & $\begin{array}{l}\text { Rolen banaketarik ez nodoen artean. } \\
\text { Erabaki guztiak autonomoak izatearen beharra, } \\
\text { beste nodoen egoerarekiko independenteak. }\end{array}$ \\
\hline 2. Edozein gailutan operatibo & $\begin{array}{l}\text { Sentsore, posizio teknologia edo gailu gehiga- } \\
\text { rrien erabilpenik ez bideen kalkulurako. }\end{array}$ \\
\hline \multicolumn{2}{|l|}{ 3. Edozein agertokitan egokitasuna } \\
\hline $\begin{array}{l}\text { 3.1. Sare-konfigurazio eta eskala } \\
\text { desberdinetarako egokigarri- } \\
\text { tasuna }\end{array}$ & $\begin{array}{l}\text { Proaktibo eta erreaktibo modurako aldaketa. } \\
\text { Modulu kognitiboaren erabilpena, sare-egoera- } \\
\text { ren arabera operazio modua aukeratzeko. }\end{array}$ \\
\hline $\begin{array}{l}\text { 3.2. Sare-aldaketera egokigarrita- } \\
\text { suna }\end{array}$ & $\begin{array}{l}\text { Bide proaktiboen mantenimendua matxurak } \\
\text { ekiditeko. }\end{array}$ \\
\hline \multicolumn{2}{|l|}{ 4. Baliabideen erabilera eraginkorra } \\
\hline $\begin{array}{l}\text { 4.1. Throughput-aren maximiza- } \\
\text { zioa }\end{array}$ & $\begin{array}{l}\text { Protokolo-gainkargaren murrizketa konbergen- } \\
\text { tzia mekanismoak ekidinez. } \\
\text { Bide proaktiboen mantenimendua bide akti- } \\
\text { boentzat soilik. }\end{array}$ \\
\hline 4.2. Potentziaren minimizazioa & $\begin{array}{l}\text { Bidalitako protokolo-mezu kopurua gutxitzea. } \\
\text { Beharrezko prozesamenduaren txikiagotzea. }\end{array}$ \\
\hline 4.3. Biltegiratzearen minimizazioa & Protokolo-mezu mota eta kopuruaren murrizketa. \\
\hline $\begin{array}{l}\text { 4.4. CPU erabilpenaren minimiza- } \\
\text { zioa }\end{array}$ & $\begin{array}{l}\text { Optimizazio-algoritmo iteratiboen ekiditea exe- } \\
\text { kuzio denboran. } \\
\text { Egokitzapen-prozesuaren konplexutasunaren } \\
\text { mugiketa entrenatze-fase offline batera. }\end{array}$ \\
\hline 5. Atzerapenaren minimizazioa & $\begin{array}{l}\text { Konbergentzia-mekanismoen ekiditea. } \\
\text { Optimizazio-algoritmo iteratiboen ekiditea pro- } \\
\text { tokoloaren exekuzioan. } \\
\text { Protokoloaren konplexutasuna bere operaziotik } \\
\text { ateratzea. } \\
\text { Protokolo-pakete gutxiren erabilpena. }\end{array}$ \\
\hline
\end{tabular}


Diseinu-gidalerro hauek modulu kognitiboan sartu behar dira, zeinak sarearen egoera detektatuko duen, nodo bakoitzean biltegiratutako bideraketa-protokoloen goiburuak eta taulak interpretatuz. Gai nagusietako bat sare-geruza adimentsuari erabakiak hartzeko ahalmena emango dioten machine learning teknikak aukeratzea da. Arestian aipatutako helburu teknikoak ez dira bateragarriak ikasketa-algoritmoen izaera iteratiboarekin, hauek prozesamendu-atzerapena handitzen baitute, eta biltegiratze eta prozesamendu-baliabide gehiago behar baitituzte. Modulu kognitiboa aurretiko ikerketa fase offline batean entrenatzea da eragozpen kritiko honen ebazpidea. Era honetan, ikerketa-prozesuaren konplexutasuna bideraketa-funtzionalitatearen operazio erregularretik at mugitzen da, eta modulu kognitiboak entrenatze-fasean irabazitako ezagutza eta detektatutako sareegoeraren arabera bideraketa-protokoloak proaktibo edo erreaktibo moduan jokatu duen erabakiko du soilik.

\subsection{Modulu kognitiboaren diseinua}

Behin sare-geruza kognitiboaren operazio-helburuak definituta eta diseinu-gidalerroak ezarrita, azpiatal honek modulu adimentsuaren diseinurako erabilitako metodologia eta erremintak deskribatzen ditu. Diseinu-metodologia honen bost faseak aurkeztuko ditugu ondoren; 1. irudian, prozesu hori laburbiltzen da.

\subsubsection{Fasea: Oinarrizko bideraketa protokoloaren aukeraketa}

Lehenengo urratsa modulu kognitiboak erabiliko duen oinarrizko bideraketa-protokoloa aukeratzea da. Ad hoc On-Demand Distance Vector $(A O D V)$ agertoki gehienetan errendimendu orokor onena ematen duen bideraketa-protokoloa da, [6] lanean ondorioztatutakoaren arabera. Hori dela eta, protokolo erreaktibo hori erabiliko da sare-mailan modulu kognitiboarekin batera. Horrez gain, analisi honetan AODV-ren portaera degradatzen den agertokiak identifikatuko dira, eta modulu kognitiboak modu pseudoproaktiboa behartuko du bide aktiboen mantenimendurako.

\subsubsection{Fasea: Bideraketa-protokoloaren errendimendurako faktore nagusien identifikazioa}

Agertoki baten definizioa parametro hauen bitartez egiten da: agertokiaren tamaina, bideraketa-protokoloa, mugimendu-eredua, abiadura, nododentsitatea eta trafiko-dentsitatea. Fase honetako helburua faktore deskribatzaile horien adierazgarritasuna aztertzea da. Analisi horren emaitzaren arabera, sarearen portaeraren azalpenean eragina ez duten parametroak modulu adimentsuaren diseinutik baztertuko dira. Hori dela eta, bariantzaren analisia (ANalysis Of Variance, ANOVA) egin da. ANOVA inferentzia estatistikorako askotan erabiltzen den metodoa da [7]. 
Sareari adimena gehitzen: machine learning eta gaitasun kognitiboen sarrera sare-mailako monitorizaziorako eta matxuren diagnostikorako

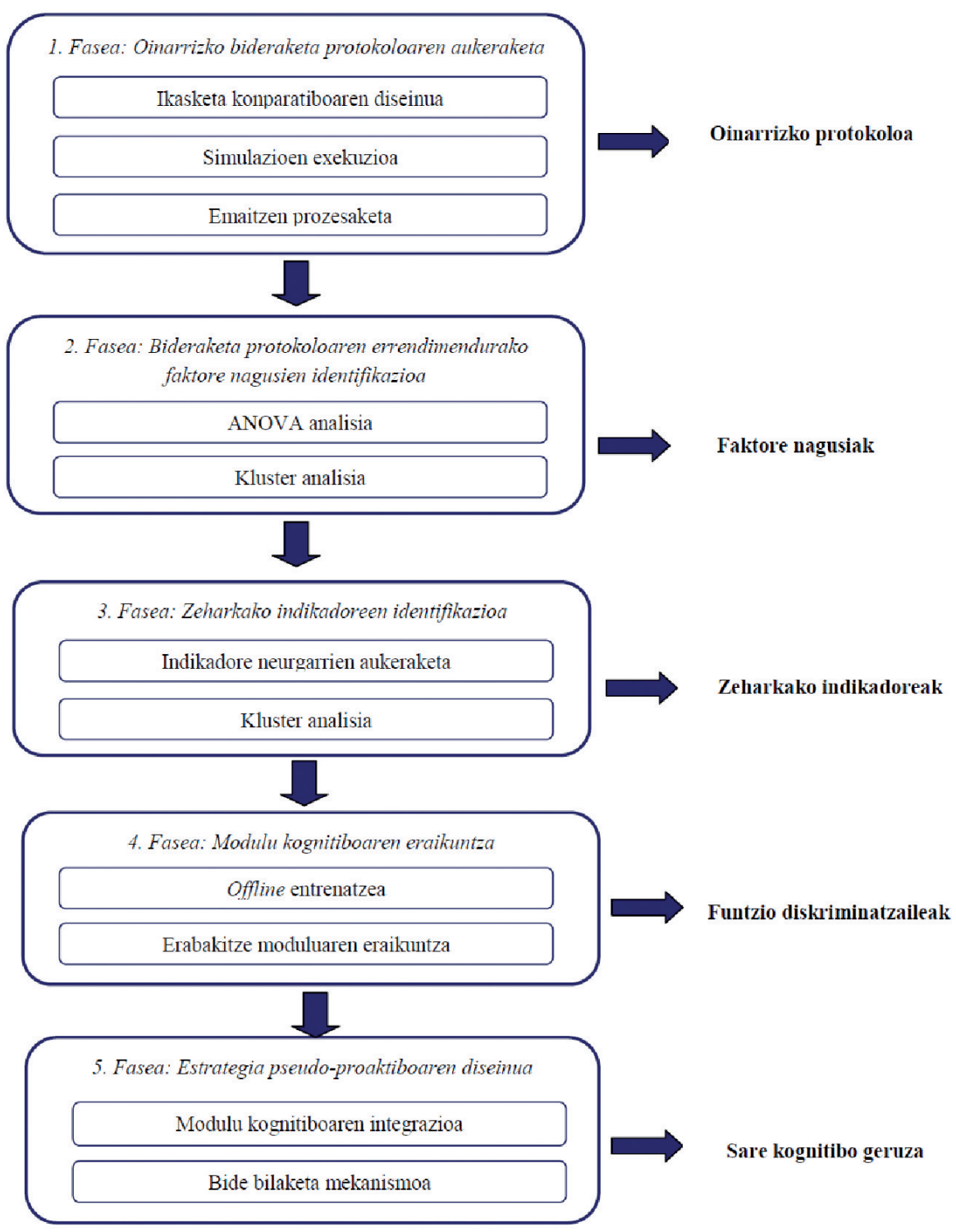

1. irudia. Modulu kognitiboaren diseinu-metodologia.

Lehendabizi, sarearen portaera azaltzeko sei metrika neurtu dira: bateriaren kontsumoa, aplikazio mailako goodput-a, muturretik muturrerako atzerapena, errore tasa, bide bakoitzeko jauzi kopurua eta protokolo-gainkarga guztirako trafikoaren arteko ratioa. Gero, bariantzaren analisi diskriminatzai- 
lea burutu da, faktore deskribatzaile bakoitzak metrika ezberdin bakoitzean duen eragina ezagutzeko. Bariantzaren analisi diskriminatzaile horren emaitzak parametro esanguratsuenak honako hauek direla adierazten du: sarearen tamaina hedapenari dagokionez, nodo-dentsitatea eta trafiko-dentsitatea, mugimendua tamaina handiko agertokietan soilik delarik esanguratsua.

Ondoren, aurreko ANOVA ikerketako emaitzetatik abiatuz, machinelearning-ean oinarritutako kluster analisia [8] egin da errendimendu metrika klasikoen bidez portaera klaseak zehazteko. Metrikak, berriro ere, bateriaren kontsumoa, aplikazio mailako goodput-a, muturretik muturrerako atzerapena, errore tasa, bide bakoitzeko salto kopurua eta protokolo gainkarga guztirako trafikoaren arteko ratioa dira.

Kontsideratuko diren portaera klase kopurua zehazteko, klustering prozesu hierarkiko aglomeratiboa erabili da; modu horretan, datuak zenbait mailatan sailkatu dira eta kluster zuhaitza edo dendrograma eraiki da. Prozesua lagin bakoitzari bere klasea esleituz hasten da, laginen arteko distantziaren arabera klaseak kluster hazkorretan taldekatuz. Dendrograma erresultantea 2. irudian azaltzen da. Han, bi klase izatearen hipotesia baliagarria dela irudikatzen da, bi azpiklusterren artean distantziarik luzeena lortzen baita.

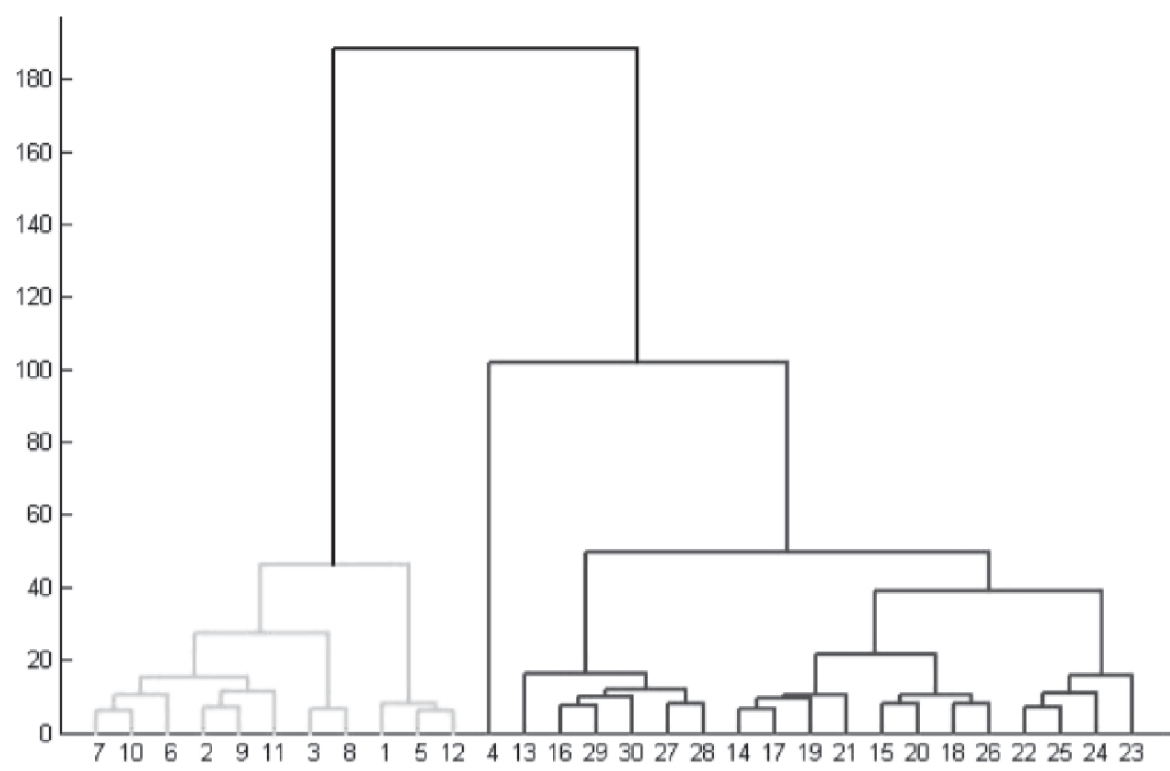

2. irudia. Faktore nagusien sailkapenaren dendrograma.

Ondorioz, AODV-ren portaera errendimendu-metrika tradizionalen bidez sailka daitekeela baieztatzen da, eta estrategia proaktiboa hobea duten kasuak diskriminatzen dira. 
Sareari adimena gehitzen: machine learning eta gaitasun kognitiboen sarrera sare-mailako monitorizaziorako eta matxuren diagnostikorako

\subsubsection{Fasea: Zeharkako indikadoreen identifikazioa}

Aitzitik, aurreko faktore nagusi horiek ez dira neurgarriak sare-mailan. Arrazoi horregatik, modulu kognitiboaren diseinuan hurrengo pausua sare-mailan eskuragarri dauden faktore nagusiekin mapeatzen diren zeharkako indikadoreak zehaztea da. Sare-geruzan eskuragarri dagoen informazioa paketeen goiburuan erantsita dagoen protokolo datuekin eta nodo bakoitzeko sare-mailako egituretan (bideraketa-tauletan eta auzoko tauletan) biltegiraturako protokolo datuekin erlazionatuta dago. Modu honetan, saregeruzan eskuragarri dauden sarearen egoeraren indikatzaileak bideraketa taulan dauden bide aktibo kopurua, auzoko nodo kopurua, aurreko nodo kopurua, jasotako errore mezu kopurua eta bidalitako errore mezu kopurua dira. Hala ere, aldagaien arteko dependentzia lineala ekiditeko, korrelazio analisi baten bidez, ikusi da erlazio zuzena dagoela aurreko nodo kopuruaren eta bide aktiboen artean, eta jasotako eta bidalitako errore mezuen artean; hori dela eta, bikote horietatik indikatzaile bakarra erabiliko da.

Faktore nagusiekin lortutako agertoki taldeak eta aukeratutako zeharkako indikadoreekin eskuratutakoak baliokideak direla egiaztatzeko, zeharkako indikadoreekin beste kluster prozesu bat gauzatu da. Kasu honetan, kluster kopurua aldez aurretik ezaguna denez, ez da kluster prozesu hierarkikorik erabili. Beraz, zuzenean k-means clustering erabili da, laginak bi taldetan sailkatuz. Bi kasuetan antzeko klusterrak lortu dira, eta hortaz, sare-mailan neurgarriak diren zeharkako indikadore horiek baliagarriak dira bideraketa mota aukeratzeko erabakiak hartzeko ardura duen modulu kognitiboa elikatzeko.

\subsubsection{Fasea: Modulu kognitiboaren eraikuntza}

Prozesu kognitiboaren erabakien efektua sare-egoerari buruzko informazio kantitatearen araberakoa da. Kasu idealean, ziklo kognitiboak uneko sare-egoeraren informazio osoa izango luke, baina sare konplexuetan kostea ez litzateke bideragarria izango. Arestian ezarritako gidalerroen arabera, arazo horri aurre egiteko, ikerketa- prozesu bat exekutatuko da aurreko entrenatze-fase offline batean. Alternatiba horrek sarearen informazio osoa izatea ahalbidetuko du, baina operazio-denboran exekutatzen den fase bakarra erabakia izango da, protokoloaren gainkarga eta prozesamendu informazio gehiagarria ekidinez. Bestalde, etorkizuneko erabakien eraginkortasuna entrenamendurako aukeratutako lagin multzoaren egokitasun eta osotasunaren araberakoa da.

Offline ikerketa-prozesu bat aukeratzeak eragiten du sare-geruza adimentsuaren beharretara hobekien egokitzen den ziklo kognitiborako soluzioa Nodo Berkonfiguragarri eredua [9] izatea. Eredu horrek garapenean dauden 5G sareetan erabiltzeko aukera egokia dirudi [10]. Arkitektura honek nodo behaketa eta akzio faseak dituen nodo berkonfiguragarri atal bat 
banatzen ditu ikasketa-gaitasunak dituen motore kognitibotik. Beraz, exekuzio-denboran, nodo berkonfiguragarriaren atala soilik inplementatzen da sare-geruzan, motore kognitiboaren atala aurreko entrenatze-fase offline baten soilik exekutatzen den bitartean.

Hortaz, sare-geruza kognitiboa hasierako entrenamendu-fase eta ondorengo exekuzio- edo erabaki-fase batez osatuta dago. Offline entrenatzefasean, kluster prozesuaren irteera beste diskriminatzaile sailkapen analisi baten sarreratzat hartzen da. Oinarrizko bideraketa-protokoloaren portaera eskualde desberdinak banatzen dituzten muga funtzioak ematen ditu sailkapen-analisi horrek. Exekuzio-denboran, nodo birkonfiguragarrian inplementatutako erabaki-faseak muga horiek sartzen ditu, eta horiek era lokalean nodo bakoitzean monitorizatzen ari diren zeharkako indikadoreetan aplikatzen dira. Kalkulu honen emaitza une bakoitzean eta sareko nodo bakoitzean bideraketa estrategia egokiena erabakitzeko erabiltzen da.

\subsubsection{Fasea: Estrategia pseudo-proaktiboaren diseinua}

Bukatzeko, estrategia pseudoproaktiboaren diseinua landu beharra dago, zeina oinarrizko protokoloaren jatorrizko modu erreaktiboarekin konbinatzen den. Hartutako soluzioa AODVren bide aurkikuntza mekanismoaz aprobetxatzen da, beharrezkoa denean bere izaera asinkronoa aldatuz eta periodikoa bilakatuz. Modulu kognitiboak operazio agertokia AODVrentzat kaltegarria dela detektatzen duenean, modu pseudoproaktiboa aktibatzen da. Momentu horretan, bideraketa-taulako helmuga aktiboetara bideak aurkitzeko prozesuak programatzen dira, bide-eskaeraren mezu sintetikoak jaurtiz. Bide egokiagoa aurkitzen bada, bideraketa-taulan dagoena ordezkatzen da. Bideraketa-taularen mantenimendu proaktiboak matxurak aurrez ematen ditu, errore batek komunikazioa eten baino lehen bide hobe batera aldatuz, horrela throughput-a gutxituz eta muturretik muturrerako atzerapena handituz, haustutako bidea konpontzeko edo helmugara bide berria aurkitzeko beharra dela eta.

\section{EMAITZEN ANALISIA}

Atal honetan, proposatutako bideraketa-estrategiaren errendimendu azterketa egiteari ekingo zaio. Modulu kognitiboan oinarritutako gure proposamen horri Glocal Ad hoc Routing Intelligence (GARI) deitu izan diogu.

Modulu kognitiboaren diseinu-printzipioetako bat bi ad hoc bideraketa protokolo moten konbinaketa da: proaktiboa eta erreaktiboa. Arrazoi horrengatik, balidatze-prozesu hau GARI eta beste ad hoc bideraketa-protokoloen alderatzean zentratzen da. Kasu honetan, aukeratutako protokoloak proaktiboa den Destination-Sequenced Distance-Vector (DSDV) eta 
Sareari adimena gehitzen: machine learning eta gaitasun kognitiboen sarrera sare-mailako monitorizaziorako eta matxuren diagnostikorako

erreaktiboa den AODV dira, azken hau modulu kognitiboaren oinarrizko bideraketa protokoloa. Atal honen helburua, alde batetik, sare-maila kognitiboan oinarritutako proposamenaren errendimendua aztertzea da, AODV eta DSDVrekin erkatuz. Beste alde batetik, implementatutako ziklo kognitiboa oinarrizko AODVrentzat agertoki kaltegarriak identifikatzeko eta pseudoproaktibo operazio modura aldatzeko gai dela egiaztatu nahi da.

Ebaluaketa simulazio-ingurune batean egin da, ausazko trafiko eta mugimendu datuak erabiliz. Agertokien konfigurazioak kontenplatzen ditu hiru simulazio-esparru tamaina (txikia: $50 \mathrm{~m} \times 50 \mathrm{~m}$; ertaina: $500 \mathrm{~m} \times 500 \mathrm{~m}$; handia: $1.000 \mathrm{~m} \times 1.000 \mathrm{~m}$ ), bi nodo-dentsitate, bi trafikodentsitate, hiru nodoen abiadura eta lau mugimendu-eredu. Agertoki bakoitza diseinu-faktore horien permutaziotzat eraikitzen da.

Emaitzek modulu kognitiboak oinarrizko AODVrentzat kaltegarriak diren agertokiak era egokian identifikatzen dituztela egiaztatzen dute, eta AODVren jatorrizko portaera hobetzen dela. Balidatze-ikerketa honen emaitzak 3. irudian aurkezten dira. Irudi horren grafikoetan ikus daitekeenez, GARIk eta AODVk portaera bera erakusten dute tamaina txikiko agertokietan. Horren arrazoia da modulu kognitiboak agertoki hauetan GARIk bere jatorrizko erreaktibo-operazioa aldatu behar ez duela erabakitzen duela, AODV bezala lan eginez.
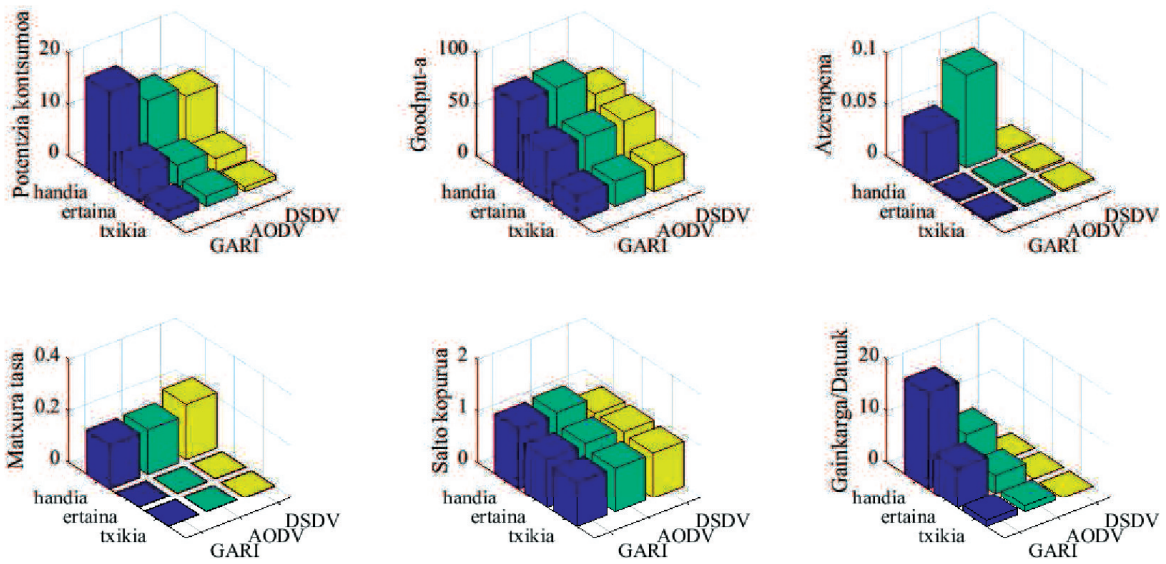

3. irudia. Errendimendu globalaren emaitzak.

Aldaketa nabaritzen hasten da tamaina ertaineko agertokian, zeinetan GARI-k bere bateria kontsumoa pixka bat handitzen duen protokolo-gainkargaren hazkunde geldoaren ondorioz. Agertoki honetan GARIk pseudoproaktibo modua eraginkorragoa den egoerak detektatzen ditu batzuetan. Baina, aldi berean, protokolo-mezuen hazkundea sortzen du afektatuko no- 
doen bide aktiboen mantenimendu proaktiboa dela eta. Bestalde, onura bezala, muturretik muturrerako atzerapena \% 1.6 murrizten da, aplikazio-mailako goodput-a \% 0.06 hazten da, eta errore-tasa \% 2.3 gutxiagotzen da.

GARIren hobekuntza nabariena AODVrekiko tamaina handiko agertokian gertatzen da. Era honetan, aipagarriena muturretik muturrerako atzerapenaren \% 37ko murrizketa da, ondoen portatzen den DSDV-rekin aldea $\%$ 28ra gutxituz. Bestalde, AODVrekin konparatuta, \% 1eko hobekuntza dago goodput-ean, eta errore-tasa \% 4an jaisten da. Beraz, baieztatzen da sare-geruza kognitibo berri hau gai dela bideraketa-taula mantenimendu proaktiboa gauzatzeko, bide matxurak aurreratzeko eta errorea gertatu baino lehen aukera egokiena beti konfiguratzeko.

\section{ONDORIOAK}

Gailu mugikor autonomo edo erdi-autonomoen hazkundeak sare-arkitektura tradizionalak zalantzan jartzen ditu, konektibitate-eskaeren hazkundea dela-eta saturatzen ari direlarik. Egungo sarearen konplexutasun-mailak, eta espero den handitzeak, sarearen eskalabilitatea bermatzeko trafikoaren monitorizazio eta analisirako paradigma berrien beharra sustatu du.

Aurkezten den artikuluak sarearen operazioan machine learning teknikak sartzen ditu, modu honetan datu-paketeei erantsitako protokolo-goiburuetatik lortutako eta sare-nodoetan protokoloaren exekuzioaren ondorioz sortutako informazioa erabili ahal izateko. Informazio hau, ziklo kognitibo baten bidez, ezagutzan eraldatzen da, sarearen egoera jakiteko eta detektatutako disfuntzioetara erreakzionatzeko ahalmena emanez.

Proposatutako metodologia ad hoc sareetan bideraketa-funtzionalitatea gauzatzeko modulu kognitibo baten diseinurako era arrakastatsuan aplikatu da. Emaitza sare-maila adimentsu bat da, zeinetan erabakiak hartzeko prozesua era autonomoan eta banatuan exekutatzen den. Modulu kognitiboak sare-egoeraren monitorizaziorako eta sare-matxurak ekiditeko sistema-informazioa biltzen du, sare-trafikoa orekatuz guztirako errendimenduan hobekuntza nabaria lortzeko.

Metodologia hau, hemen ad hoc sare mugikorren inguruan aplikatu dena, guztiz estrapolagarria da beste edozein teknologiatan edo sare motatan. Bideraketa-filosofia berri bat aurkezten du, zeinak bere operazioa ad hoc sareen aplikazio-inguruneen ezaugarri espezifikoetara eta horien exekuzio denborako aldaketetara moldatzen duen. Modulu kognitiboaren inplementazioari esker, bideraketa funtzionalitateak oinarrizko protokoloaren portaera hobetzen du, eta haren funtzioa barietate handiko aplikazio desberdinen errendimendu behar globaletara egokitzen da, era banatuan eta auto-antolatuan lan eginez. 
Sareari adimena gehitzen: machine learning eta gaitasun kognitiboen sarrera sare-mailako monitorizaziorako eta matxuren diagnostikorako

Stream datuen meatzaritzan memoria-limitazioak, erantzunen azkartasuna, online ikasketa, concept drift eta beste zenbait problemari aurre egiteko baliagarriak suerta daiteztekeen teknikak eskaintzen dira. Era honetan, lan hau offline ikasketan zentratzen bada ere, etorkizunerako planteatzen da landutako problema stream datuen meatzaritza erabiliz aztertzea.

\section{BIBLIOGRAFIA}

[1] MICHALSKI, R.S., CARBONELL, J.G., MITCHELL, T.M. 2013. Machine learning: An artificial intelligence approach, Springer Science \& Business Media, Berlin.

[2] BIGLIERI, E., GOLDSMITH, A.J., GREENSTEIN, L.J., MANDAYAM, N.B., POOR, H.V. 2013. Principles of Cognitive Radio, Cambridge University Press, London.

[3] BASAGNI, S. et al. 2013. Mobile Ad Hoc networking: the cutting edge directions. John Wiley \& Sons, Hoboken.

[4] CONTI, M., GIORDANO, S. 2014. «Mobile ad hoc networking: milestones, challenges, and new research directions». IEEE Commun. Mag., 52(1): 8596.

[5] UMAMAHESWARAN, S., KUMAR, N., BISWAS, P.K. 2014. «A survey of routing protocol design patterns for mobile ad hoc networks». In Proceedings of 2014 2nd International Conference on Emerging Technology Trends in Electronics, Communication and Networking, 1: 1-6.

[6] BLANCO, B., LIBERAL, F., TABOADA, I. 2013. «Suitability of ad hoc routing in WNR: Performance evaluation and case studies». Ad Hoc Networks, 11(3): 1165-1177.

[7] GOSWAMI, S., JOARDAR, S., DAR, C.B., KAR, S., PAL, D.K. 2017. «Performance Analysis of Three Routing Protocols in MANET Using the NS-2 and ANOVA Test with Varying Speed of Nodes». Ad Hoc Networks. In Tech.

[8] MIRKIN, B. 2012. Clustering: A Data Recovery Approach. CRC Press.

[9] SUTTON, P., DOYLE, L.E., NOLAN, K.E. 2006. «A Reconfigurable Platform for Cognitive Networks». In Proceedings of IEEE International Conference on Cognitive Radio Oriented Wireless Networks and Communications, 1: $1-5$.

[10] BLANCO, B., FAJARDO, J.O., LIBERAL, F., TABOADA, I. 2017. «Gaitasun kognitiboen aplikazioa $5 \mathrm{G}$ sareetako kontrol eta kudeaketa mailetan». EKAIA Euskal Herriko Unibertsitateko Zientzi eta Teknologi Aldizkaria, 31: 145-156. 